\title{
CD95L and Anti-Tumor Immune Response: Current Understanding and New Evidence
}

This article was published in the following Dove Press journal:

Cancer Management and Research

\author{
David M Richards \\ Christian Merz \\ Christian Gieffers \\ Andriy Krendyukov (D) \\ Apogenix AG, Heidelberg, Germany
}

\begin{abstract}
The ability of FasL/CD95L to induce apoptosis in various Fas/CD95-expressing cells has been described in the context of hematopoiesis or thymic elimination of selfreactive $\mathrm{T}$ cells and resolution of an acute immune response under physiological conditions. At the same time, non-apoptotic CD95 activation is widely described in cancer and shown to stimulate invasiveness of cancer cells, promote cancer progression as well as stemness of cancer cells. This paper puts emphasis on the evolving understanding of expression and the non-apoptotic activities of the CD95/CD95L signaling pathway on the function of tumor cells, tumor microenvironment and immune cells. The emerging evidence to support the role of CD95/CD95L signaling in the anti-tumor immune response will be presented in the context of various malignancies and the modalities of potential therapeutic interventions via selective CD95L inhibition in combination with traditional interventions such as RT, chemotherapy and immune checkpoint inhibitors.
\end{abstract}

Keywords: FasL/CD95L, anti-tumor immune response, immune checkpoint, tumor microenvironment, novel therapeutic target

\section{Introduction}

The textbook prototype of pro-apoptotic signaling pathways is the Fas/CD95 and FasL/CD95L (also termed APO-1 and Apo1-L, respectively) system. Apoptosis is induced by binding of CD95L to CD95 and orchestrated at the CD95 intracellular death domain (DD) through assembly of the death-inducing signaling complex (DISC). DISC assembly either leads to activation of a caspase-dependent (type I) cellular suicide program or cross-induction of the mitochondrial (type II) pathway, depending on the cell type and the extent of DISC activity. ${ }^{1}$ The ability of CD95L to induce apoptosis in various CD95expressing cells has been described in the context of hematopoiesis ${ }^{2}$ or thymic elimination of self-reactive $\mathrm{T}$ cells ${ }^{3}$ and resolution of an acute immune response $^{4,5}$ under physiological conditions.

However, despite the finding that most cell types constitutively express CD95, many are resistant to apoptosis induction by CD95L. Especially in cancer, nonapoptotic CD95 activation is widely described and shown to stimulate invasiveness of cancer cells, ${ }^{6,7}$ promote cancer progression ${ }^{8}$ as well as stemness of cancer cells. $^{9,10}$ Interestingly, synthetic knockout of CD95 or CD95L has been demonstrated to induce cell death by a process termed DICE (death induced by CD95R/L elimination). ${ }^{11}$ Extensive studies of CD95/CD95L interactions have expanded and diversified our understanding of this multi-faceted couple, for example:
Correspondence: Andriy Krendyukov Tel +49 622I 5860877

Email andriy.krendyukov@apogenix.com
Cancer Management and Research 2021:13 2477-2482

2477

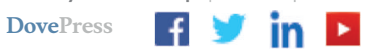

(c) (i) (5) 202I Richards et al. This work is published and licensed by Dove Medical Press Limited. The full terms of this license are available at https://www.dovepress.com/terms. cc. work you hereby accept the Terms. Non-commercial uses of the work are permitted without any further permission from Dove Medical 
- CD95 and CD95L are both present in membraneanchored and soluble forms, but are created differently: sCD95 is generated by alternative splicing ${ }^{12}$ in contrast to $\mathrm{sCD} 95 \mathrm{~L}$, which is produced by shedding through metalloproteases. ${ }^{13}$

- Soluble CD95L has no proapoptotic activity, ${ }^{14}$ but acts as a chemoattractant for T cells. ${ }^{15}$

- The intracellular domain of CD95L possesses backsignaling activity. ${ }^{16,17}$

- Posttranslational modifications of both CD95 and CD95L change their stability and biological function. ${ }^{18-21,52-54}$

In this review, we put emphasis on understanding the expression and non-apoptotic activities of CD95/CD95L signaling in the context of various malignancies and modalities of potential therapeutic interventions.

\section{Emerging Evidence of the Role CD95 and CD95L Play in the Anti-Tumor Immune Response}

CD95 and CD95L are expressed on multiple cell populations found in the tumor tissue (Table 1) and they are often both expressed on the same cell. In the following section, we will describe the role of the CD95/CD95L signaling pathway on the function of tumor cells, other cells found in the tumor microenvironment (TME) and, ultimately, immune cells.

\section{CD95/CD95L Expression on Tumor Cells}

Tumor cells have been shown to express both CD95 and CD95L. Interestingly, our understanding of the contribution of each pathway towards cancerogenesis has significantly changed over the last 10 years. Originally, it was thought that CD95L-mediated killing of CD95-expressing tumor cells was an important mechanism used by the immune system to eliminate cancer cells. In fact, and as described below, it seems to be just the other way around. First of all, the literature is filled with examples of cancers reducing surface expression of CD95 in order to evade immune cell-mediated killing. Recently published evidence has shed light on the specific mechanisms used by these tumor cells to escape death. This includes changes in endo-lysosomal trafficking that result in feedback loops decreasing CD95 expression as well as enrichment of CD95L-insensitive tumor cells following treatment with immune checkpoint inhibitors. ${ }^{22,23}$
Furthermore, although often associated with apoptosis, CD95/CD95L signaling in tumor cells also has many direct pro-tumor functions, including the generation of survival signals. ${ }^{24}$ For example, CD95L signaling contributes to the metastatic spread of cancer cells. ${ }^{25}$ The mechanisms of these pro-survival signals have been recently described where it was shown that CD95CD95L interactions mediate a paracrine signal that is essential for cancer cell survival. ${ }^{26}$ In addition, chronic signaling through CD95 was shown to increase the cancerinitiating capacity in breast cancer. ${ }^{10}$ It has been found that CD95 is part of a larger regulatory network that drives cancer stemness and contributes to anti-cancer therapy resistance. Furthermore, the 3D-organization of the CD95ligand and -receptor complexes determines whether signaling leads to apoptosis or survival. ${ }^{27}$ These results are consistent with the activity of other members of this protein superfamily.

\section{CD95/CD95L Expression on Other Cells in the Tumor Microenvironment}

More evidence is emerging describing the importance of the TME in determining which role CD95/CD95L plays in the anti-tumor response. ${ }^{28}$ While tumor cells themselves can directly express both the CD95 receptor and ligand, it has been shown that tumor-derived factors such as vascular endothelial growth factor A (VEGF-A), interleukin 10 (IL-10) and prostaglandin E2 (PGE2) cooperatively induce CD95L expression on other cells in the TME. ${ }^{29-32}$

For example, CD95L has been detected in the vasculature of both human and murine tumors. ${ }^{31,37,55}$ These CD95L-expressing endothelial cells create a barrier to $\mathrm{CD} 8+\mathrm{T}$ cell infiltration and tumor cell elimination. Interestingly, genetic or pharmacological blockade of CD95/CD95L signaling increased $\mathrm{T}$ cell infiltration leading to tumor growth inhibition. ${ }^{31}$

It has also been shown that polymorphonuclear myeloid-derived suppressor cells (MDSC) found in the TME express high levels of $\mathrm{CD} 95 \mathrm{~L}$ and contribute to apoptosis of tumor-specific CD8+ T cells. ${ }^{30}$ In this model, blockade of CD95/CD95L signaling also conferred a beneficial effect by reducing $\mathrm{T}$ cell apoptosis and increasing the efficacy of immune checkpoint inhibitor therapy.

Finally, cancer-associated fibroblasts (CAF) can be educated by the tumor cells to express high levels of CD95L and contribute to the elimination of tumor-specific CD8+ $\mathrm{T}$ cells. ${ }^{32} \mathrm{CAF}$, purified from human tumor tissue, were 
Table I CD95 and CD95L Expression in Tumors

\begin{tabular}{|c|c|c|}
\hline Tumor Type & Cell Type Expressing CD95L & The Role of CD95-CD95L Signaling Pathway in Cancer Pathogenesis \\
\hline $\begin{array}{l}\text { - Melanoma } \\
\text { - Lung carcinoma } \\
\text { - Hepatocellular } \\
\text { carcinoma } \\
\text { - Oesophageal } \\
\text { carcinoma } \\
\text { - Colon carcinoma } \\
\text { - Ovarian } \\
\text { carcinoma } \\
\text { - Glioblastoma } \\
\text { - Pancreatic } \\
\text { adenocarcinoma } \\
\text { - Head and neck } \\
\text { carcinoma }\end{array}$ & $\begin{array}{l}\text { - Cancer cells } \\
\text { - Effector T cells (CD8+) } \\
\text { - Regulatory T cells (CD4+, } \\
\text { CD25+) } \\
\text { - Tumor endothelial cells } \\
\text { - } \text { Myeloid-derived suppressor } \\
\text { cells (MDSC) } \\
\text { - } \text { Monocyte-derived human } \\
\text { macrophages (MDM) } \\
\text { - Cancer-associated fibroblasts } \\
\text { (CAF) } \\
\text { - Cancer stem cells (CSC) }\end{array}$ & $\begin{array}{l}\text { - High malignancy of FasL/CD95L tumor cell (growth and invasion) } \\
\text { - Pro-tumoral role of CD95L } \\
\text { - CD95L mediated apoptosis of CD8 T cells by CD95L-expressing endothelial cells } \\
\text { - Poor CD8 T cell infiltration association with CD95L-expressing endothelial cells } \\
\text { (extravasation and infiltration) } \\
\text { - Apoptosis of Fas/CD95-expressing anti-tumor immune effector cells } \\
\text { - T cell deletion mediated by CD95L-expression by MDSC } \\
\text { - Apoptosis of CD8 T cells by CD95L and PD-L2 expressed on CAFs } \\
\text { - Tregs expressed high level of CD95L (observed in cancer patients) - might suppress } \\
\text { proliferation and induce CD8 T cell apoptosis }\end{array}$ \\
\hline
\end{tabular}

shown to present tumor-derived antigens to CD8+ T cells and kill them in the process via PDL-2 and CD95Ldependent mechanisms. Once again, inhibition of CD95/ CD95L signaling reactivated $\mathrm{T}$ cell-mediated killing of tumor cells both in vivo and in vitro.

\section{CD95/CD95L Expression on Immune Cells}

CD95L is classically associated with the effector function of cytotoxic T cells. Cytotoxic T lymphocytes (CTL) use multiple partially redundant pathways, including the cytotoxins perforin, multiple granzymes, and granulysin as well as cytolytic cytokines interferon-gamma, tumor necrosis factor-alpha and lymphotoxin-alpha, to eliminate their targets. $^{33,34}$

In fact, CD95/CD95L signaling has been shown to play less of a role in eliminating foreign antigens and more of a role in resolving acute immune responses, limiting overshooting immune responses and maintaining peripheral immune tolerance through a mechanism commonly called activation-induced cell death (AICD). ${ }^{4,35,36}$

In the context of cancer cell's resistance to therapy, it has been described that these mechanisms are being exploited to limit (stall) the anti-tumor immune response. In fact, intra-tumoral apoptosis of tumor-specific $T$ cells is a major limitation to the development of effective immunotherapeutic strategies. ${ }^{38}$ As mentioned above, multiple different stromal cell populations contribute to increase expression of CD95L and directly enhance $\mathrm{T}$ cell death. $^{30-32}$
Recent developments in the field of chimeric antigen receptor (CAR) $\mathrm{T}$ cells have provided direct evidence of the role that CD95L plays in T cell survival. By having the ability to genetically and pharmacologically modify and later monitor specific $\mathrm{T}$ cell populations over time, it has been possible to show that CD95L-mediated signals are able to promote $\mathrm{T}$ cell dysfunction and death, predominantly via apoptotic mechanism, in vivo and in vitro. It was shown that CD95-mediated signaling impaired antitumor immunity by inducing precocious differentiation in CAR T cell preparations. ${ }^{39}$ In these heterogeneous $\mathrm{T}$ cell environments, existing memory $\mathrm{T}$ cells, expressing CD95L, accelerate the maturation of tumor-specific naïve T cells through a PI3K-mediated pathway. This accelerated maturation promotes differentiation of these $\mathrm{T}$ cells into effector memory cells that have reduced proliferative and anti-tumor activity. Subsequent results have confirmed that CAR T cells are highly sensitive to CD95L-mediated cell death. $^{40,41}$ In fact, CAR T cells significantly upregulate expression of both CD95 and CD95L as well as other important proteins associated with apoptotic cell death and AICD such as DR5 and TRAIL. ${ }^{41}$ In this context, blocking CD95/CD95L signals also increased the survival of these CAR T cells. Finally, in experiments that highlight the utility of these models, engineered CD95-deficient CAR T cells showed increased survival and developed superior efficacy against both solid and hematologic tumors. $^{29}$ One additional factor that seems to make CAR $\mathrm{T}$ cells especially good models to dissect the role that CD95/CD95L signals play in the anti-tumor immune response has to do with the affinity of CAR $\mathrm{T}$ cell 
receptors. Classically, $\mathrm{T}$ cell exhaustion, AICD and CD95L-mediated cell death are associated with chronic (or tonic) stimulation. This is especially true for CAR $\mathrm{T}$ cells which have additional co-stimulatory domains, such as CD28 and 4-1BB, engineered into the construct. These CAR T cells show increased sensitivity to CD95/ CD95L-mediated cell death due to the tonic signals coming from the co-stimulatory domains. ${ }^{40}$

Finally, recent data investigating natural anti-tumor immune cells have also provided evidence supporting the importance of TCR affinity, CD95/CD95L and T cell survival. The responses to immune checkpoint inhibitors vary depending on many factors. One relevant factor seems to be $\mathrm{T}$ cell sensitivity to apoptosis in low tumor burden states. ${ }^{42}$ In the context of low tumor burden, elevated IFNgamma production leads to a change in the sensitivity of anti-tumor $\mathrm{T}$ cells possibly due to CD95 expression. In addition, experiments that directly alter TCR sensitivity by genetically or pharmacologically inhibiting CD95 signaling in the context of anti-tumor immunity and AICD have shown that these high-affinity $\mathrm{T}$ cells undergo CD95mediated cell death and this cell death can be blocked with multiple inhibitors of CD95/CD95L signaling. ${ }^{43,44}$

\section{Selective Blockade of CD95L as Novel Potential Therapeutic Target}

The recent advances in the understanding of the CD95/ CD95L signaling pathway in cancer progression might represent a potential approach for cancer immunotherapy via selective inhibition of this interaction, particularly in combination with Immune Checkpoint Inhibitors (ICIs).

It has been shown that selective blockade of CD95L by the fully humanized recombinant fusion protein (APG101/ Asunercept) inhibits CD95L-mediated invasion of glioma cells in vitro and in vivo. ${ }^{45}$ Such selective inhibition of CD95L by this therapeutic agent, in combination with focal radiotherapy (RT), resulted in substantial reduction of tumor growth, fewer tumor satellites, reduced activity of matrix metalloproteinase as well as prolonged survival of tumor-bearing mice compared with RT alone. ${ }^{46}$

As a clinical implication, selective CD95L inhibition improved 6-month progression-free survival in combination with re-irradiation (rRT) when compared with rRT alone in a randomized Phase II proof-of-concept study conducted in patients with recurrent glioblastoma. ${ }^{47} \mathrm{In}$ a post hoc analysis, an overall survival benefit for recurrent glioblastoma patients with low methylation of the
CD95L promoter was demonstrated with the selective CD95L inhibitor plus rRT compared to rRT alone. In addition, such therapeutic combinations significantly prolonged time-to-deterioration and maintained the quality of life beyond progression of the disease versus rRT alone. ${ }^{48}$

Similar approaches to selectively inhibit CD95/ CD95L signaling have been tested in Myelodysplastic syndromes (MDS) where increased CD95L activity has been shown to result in apoptotic cell death of precursor cells and reduced hematopoiesis. ${ }^{49}$ In transfusiondependent low- and intermediate-risk MDS patients, the CD95L inhibitor APG101 preserved the capacity of erythroblasts to differentiate and reduced apoptosis of CD34 + erythrocyte precursors. ${ }^{50}$ That resulted in a decrease in transfusion need and frequency in transfusion-dependent low- and intermediate-risk MDS patients resistant to treatment with erythropoiesis-stimulating agents. ${ }^{51}$

\section{Conclusion/Opinion}

Over the recent years, more and more evidence has been published to better understand and unveil the role of the CD95/CD95L signaling pathway on the function of tumor cells, immune cells and other cells involved in cancerogenesis, qualifying this pathway as another important immune checkpoint.

Targeting the CD95/CD95L pathway via selective CD95L inhibition therefore offers a promising therapeutic approach on its own as well as in combination with traditional interventions such as RT, chemotherapy and other immune checkpoint inhibitors.

\section{Disclosure}

AK and CG are employees of Apogenix AG. DMR and $\mathrm{CM}$ are former employees of Apogenix AG. The authors report no other conflicts of interest in this work.

\section{References}

1. Barnhart BC, Alappat EC, Peter ME. The Cd95 Type I/Type II model. Semin Immunol. 2003;15(3):185-193.

2. Niho Y, Asano Y. Fas/Fas ligand and hematopoietic progenitor cells. Curr Opin Hematol. 1998;5(3):163-165.

3. Castro JE, Listman JA, Jacobson BA, et al. Fas modulation of apoptosis during negative selection of thymocytes. Immunity. 1996;5 (6):617-627.

4. Green DR, Droin N, Pinkoski M. Activation-induced cell death in T cells. Immunol Rev. 2003;193:70-81.

5. Schmitz I, Krueger A, Baumann S, Schulze-Bergkamen H, Krammer PH, Kirchhoff S. An Il-2-dependent switch between Cd95 signaling pathways sensitizes primary human $\mathrm{T}$ cells toward Cd95-mediated activation-induced cell death. J Immunol. 2003;171 (6):2930-2936. 
6. Barnhart BC, Legembre P, Pietras E, Bubici C, Franzoso G, Peter ME. Cd95 ligand induces motility and invasiveness of apoptosis-resistant tumor cells. EMBO J. 2004;23(15):3175-3185.

7. Kleber S, Sancho-Martinez I, Wiestler B, et al. Yes and Pi3k bind Cd95 to signal invasion of glioblastoma. Cancer Cell. 2008;13 (3):235-248.

8. Chen L, Park S-M, Tumanov AV, et al. cd95 promotes tumour growth. Nature. 2010;465(7297):492-496.

9. Drachsler M, Kleber S, Mateos A, et al. Cd95 maintains stem cell-like and non-classical EMT programs in primary human glioblastoma cells. Cell Death Dis. 2016;7:e2209.

10. Qadir AS, Stults AM, Murmann AE, Peter ME. The mechanism of how CD95/Fas activates the Type I IFN/STAT1 axis, driving cancer stemness in breast cancer. Sci Rep. 2020;10(1):1310.

11. Hadji A, Ceppi P, Murmann AE, et al. Death induced by Cd95 or Cd95 ligand elimination. Cell Rep. 2014;7(1):208-222.

12. Nagata S. Fas and fas ligand: a death factor and its receptor. $A d v$ Immunol. 1994;57:129-144.

13. Schulte M, Reiss K, Lettau M, et al. Adam10 regulates Fasl cell surface expression and modulates Fasl-induced cytotoxicity and activation-induced cell death. Cell Death Differ. 2007;14 (5):1040-1049.

14. O' Reilly LA, Tai L, Lee L, et al. Membrane-bound fas ligand only is essential for fas-induced apoptosis. Nature. 2009;461(7264):659-663.

15. Poissonnier A, Sanseau D, Le Gallo M, et al. Cd95-Mediated Calcium Signaling Promotes T Helper 17 Trafficking to Inflamed Organs in Lupus-Prone Mice. Immunity. 2016;45(1):209-223.

16. Kirkin V, Cahuzac N, Guardiola-Serrano F, et al. The Fas ligand intracellular domain is released by Adam10 and Spp12a cleavage in T-cells. Cell Death Differ. 2007;14(9):1678-1687.

17. Luckerath K, Kirkin V, Melzer IM, et al. Immune modulation by fas ligand reverse signaling: lymphocyte proliferation is attenuated by the intracellular fas ligand domain. Blood. 2011;117(2):519-529.

18. Feig C, Tchikov V, Schütze S, Peter ME. Palmitoylation of Cd95 facilitates formation of SDS-stable receptor aggregates that initiate apoptosis signaling. EMBO J. 2007;26(1):221-231.

19. Chakrabandhu K, Hérincs Z, Huault S, et al. Palmitoylation is required for efficient fas cell death signaling. EMBO J. 2007;26 (1):209-220.

20. Guardiola-Serrano F, Rossin A, Cahuzac N, et al. Palmitoylation of human Fasl modulates its cell death-inducing function. Cell Death Dis. 2010;1:e88.

21. Rossin A, Durivault J, Chakhtoura-Feghali T, Lounnas N, GagnouxPalacios L, Hueber AO. Fas palmitoylation by the palmitoyl acyltransferase Dhhc7 regulates fas stability. Cell Death Differ. 2015;22 (4):643-653.

22. Sharma S, Carmona A, Skowronek A, et al. Apoptotic signalling targets the post-endocytic sorting machinery of the death receptor Fas/Cd95. Nat Commun. 2019;10(1):3105.

23. Xiao W, Ibrahim ML, Redd PS, et al. Loss of Fas expression and function is coupled with colon cancer resistance to immune checkpoint inhibitor immunotherapy. Mol Cancer Res. 2019;17 (2):420-430.

24. Le Gallo M, Poissonnier A, Blanco P, Legembre P. Cd95/Fas, non-apoptotic signaling pathways, and kinases. Front Immunol. 2017;8:1216.

25. Teodorczyk M, Kleber S, Wollny D, et al. Cd95 promotes metastatic spread via Sck in pancreatic ductal adenocarcinoma. Cell Death Differ. 2015;22(7):1192-1202.

26. Luebke T, Schwarz L, Beer YY, et al. C-Flip and Cd95 signaling are essential for survival of renal cell carcinoma. Cell Death Dis. 2019;10(6):384.

27. Gulculer Balta GS, Monzel C, Kleber S, et al. 3d cellular architecture modulates tyrosine kinase activity, thereby switching Cd95-mediated apoptosis to survival. Cell Rep. 2019;29(8):2295-306 e6.
28. Thorsson V, Gibbs DL, Brown SD, et al. The immune landscape of cancer. Immunity. 2018;48(4):812-30 e14.

29. Yamamoto TN, Lee PH, Vodnala SK, et al. T cells genetically engineered to overcome death signaling enhance adoptive cancer immunotherapy. J Clin Invest. 2019;129(4):1551-1565.

30. Zhu J, Powis de Tenbossche CG, Cane S, et al. Resistance to cancer immunotherapy mediated by apoptosis of tumor-infiltrating lymphocytes. Nat Commun. 2017;8(1):1404.

31. Motz GT, Santoro SP, Wang LP, et al. Tumor Endothelium Fasl establishes a selective immune barrier promoting tolerance in tumors. Nat Med. 2014;20(6):607-615.

32. Lakins MA, Ghorani E, Munir H, Martins CP, Shields JD. Cancerassociated fibroblasts induce antigen-specific deletion of $\mathrm{Cd} 8(+)$ T cells to protect tumour cells. Nat Commun. 2018;9(1):948.

33. Golstein P, Griffiths GM. An early history of $\mathrm{T}$ cell-mediated cytotoxicity. Nat Rev Immunol. 2018;18(8):527-535.

34. Martinez-Lostao L, Anel A, Pardo J. How do cytotoxic lymphocytes kill cancer cells? Clin Cancer Res. 2015;21(22):5047-5056.

35. Mueller DL. Mechanisms maintaining peripheral tolerance. Nat Immunol. 2010;11(1):21-27.

36. Yamada A, Arakaki R, Saito M, Kudo Y, Ishimaru N. Dual Role of Fas/Fasl-mediated signal in peripheral immune tolerance. Front Immunol. 2017;8:403.

37. Malleter M, Tauzin S, Bessede A, et al. CD95L cell surface cleavage triggers a prometastatic signaling pathway in triple-negative breast cancer. Cancer Res. 2013;73:6711-6721.

38. Horton BL, Williams JB, Cabanov A, Spranger S, Gajewski TF. Intratumoral $\mathrm{Cd} 8(+)$ T-Cell apoptosis is a major component of T-cell dysfunction and impedes antitumor immunity. Cancer Immunol Res. 2018;6(1):14-24.

39. Klebanoff CA, Scott CD, Leonardi AJ, et al. Memory T cell-driven differentiation of naive cells impairs adoptive immunotherapy. J Clin Invest. 2016;126(1):318-334.

40. Gomes-Silva D, Mukherjee M, Srinivasan M, et al. Tonic 4-1bb costimulation in chimeric antigen receptors impedes $\mathrm{T}$ cell survival and is vector-dependent. Cell Rep. 2017;21(1):17-26.

41. Tschumi BO, Dumauthioz N, Marti B, et al. Cart cells are prone to Fas- and Dr5-mediated cell death. J Immunother Cancer. 2018;6 (1):71.

42. Pai CS, Huang JT, Lu X, et al. Clonal deletion of tumor-specific $\mathrm{T}$ cells by interferon-gamma confers therapeutic resistance to combination immune checkpoint blockade. Immunity. 2019;50(2):477-92 e8.

43. Alotaibi F, Rytelewski M, Figueredo R, et al. Cd5 Blockade Enhances Ex Vivo Cd8(+) T Cell Activation and Tumour Cell Cytotoxicity. Eur J Immunol. 2020. doi:10.1002/eji.201948309

44. Yamaguchi R, Perkins G. Animal models for studying tumor microenvironment (TME) and resistance to lymphocytic infiltration. Cancer Biol Ther. 2018;19(9):745-754.

45. Merz C, Strecker A, Sykora J, et al. Neutralization of the Cd95 ligand by Apg101 inhibits invasion of glioma cells in vitro. Anticancer Drugs. 2015;26(7):716-727.

46. Blaes J, Thome CM, Pfenning PN, et al. Inhibition of Cd95/Cd951 (Fas/Faslg) signaling with Apg101 prevents invasion and enhances radiation therapy for glioblastoma. Mol Cancer Res. 2018;16 (5):767-776.

47. Wick W, Fricke H, Junge K, et al. A Phase II, randomized, study of weekly Apg101+reirradiation versus reirradiation in progressive glioblastoma. Clin Cancer Res. 2014;20(24):6304-6313.

48. Wick W, Krendyukov A, Junge K, Hoger T, Fricke H. Longitudinal analysis of quality of life following treatment with asunercept plus reirradiation versus reirradiation in progressive glioblastoma patients. J Neurooncol. 2019.

49. Fontenay M, Gyan E. Apoptotic pathways to death in myelodysplastic syndromes. Haematologica. 2008;93(9):1288-1292. 
50. Raimbault A, Pierre-Eugene C, Rouquette A, et al. Apg101 efficiently rescues erythropoiesis in lower risk myelodysplastic syndromes with severe impairment of hematopoiesis. Oncotarget. 2016;7(12):14898-14911.

51. Boch T, Luft T, Metzgeroth G, et al. Safety and Efficacy of the Cd95-ligand inhibitor asunercept in transfusion-dependent patients with low and intermediate risk Mds. Leuk Res. 2018;68:62-69.

52. Seyrek K, Richter M, Lavrik IN. Decoding the sweet regulation of apoptosis: the role of glycosylation and galectins in apoptotic signaling pathways. Cell Death Differ. 2019;26:981-993.
53. Seyrek K, Lavrik IN. Modulation of CD95-mediated signaling by post-translational modifications: towards understanding CD95 signaling networks. Apoptosis. 2019;24:385-394.

54. Levoin N, Jean M, Legembre P. CD95 structure, aggregation and cell signaling. Front Cell Dev Biol. 2020;8:314.

55. Yu JS, Lee PK, Ehtesham M, Samoto K, Black KL, Wheeler CJ. Intratumoral $\mathrm{T}$ cell subset ratios and Fas ligand expression on brain tumor endothelium. J Neurooncol. 2003;64(1-2):55-61.

\section{Publish your work in this journal}

Cancer Management and Research is an international, peer-reviewed open access journal focusing on cancer research and the optimal use of preventative and integrated treatment interventions to achieve improved outcomes, enhanced survival and quality of life for the cancer patient.
The manuscript management system is completely online and includes a very quick and fair peer-review system, which is all easy to use. Visit http://www.dovepress.com/testimonials.php to read real quotes from published authors. 